\title{
Correlation between Surface Energy and Adhesion Force of Polyethylene/Paperboard: A Predictive Tool for Quality Control in Laminated Packaging
}

\author{
Danielle M. F. Madeira, ${ }^{1}$ Osvaldo Vieira $\mathbb{D}^{2},{ }^{2}$ Luís Antonio Pinheiro, ${ }^{3}$ \\ and Benjamim de Melo Carvalho ${ }^{3}{ }^{3}$ \\ ${ }^{1}$ Graduate Program in Materials Engineering/Research and Development Area, Klabin S.A., São Paulo, SP, Brazil \\ ${ }^{2}$ Department of Research and Process Development, Klabin S.A., São Paulo, SP, Brazil \\ ${ }^{3}$ Materials Engineering Department/Graduate Program in Materials Engineering, \\ State University of Ponta Grossa (UEPG), Ponta Grossa, PR, Brazil
}

Correspondence should be addressed to Benjamim de Melo Carvalho; bmcarval@hotmail.com

Received 28 February 2018; Accepted 29 April 2018; Published 3 June 2018

Academic Editor: Michael Harris

Copyright ( 2018 Danielle M. F. Madeira et al. This is an open access article distributed under the Creative Commons Attribution License, which permits unrestricted use, distribution, and reproduction in any medium, provided the original work is properly cited.

\begin{abstract}
Poor adhesion continues to be a problem for manufacturers of laminated packaging. Therefore, the aim of this research was to study the effect of flame treatment, the type of coating, and starch application on the adhesion force of polyethylene/paperboard. The force of adhesion was determined using the peel test method; the paper surface energy was assessed by contact angle analysis; and paperboard roughness was determined by profilometer. The flame treatment did not affect the surface roughness but significantly increased the paperboard surface energy. The paperboard coated with polar latex showed much higher surface energy than the paperboard coated with nonpolar latex. The adhesion force of polyethylene presented a linear correlation to the surface energy of the paperboard. Therefore, the surface energy of paperboard is an excellent indication of its adhesion force to polyethylene, and this represents a very reliable and practical method in terms of quality control in the paper industry for producing laminated packages.
\end{abstract}

\section{Introduction}

In the area of laminated packaging, good adhesion between the components is one of the most important aspects. However, poor adhesion continues to be a serious problem for manufacturers of this kind of product $[1,2]$. In a recent paper, Oliveira et al. [3] proposed a method to measure the adhesion force between plastic and aluminum layers. This test consisted of thermosealing a plastic film on the metallic surface of the packaging using specific conditions of time, temperature, and pressure. The aforementioned authors measured the adhesion force by delaminating the thermosealed plastic in a universal testing machine and applying a specific angle and speed; they concluded that this method was stable, precise, and replicable.
In long-life packaging, there is also adhesion between plastic and aluminum layers. However, the critical problem in this kind of packaging is poor adhesion between the polyethylene and the paperboard. The use of polymers laminated onto paper is very common in order to improve its properties and to increase the value of several products. However, Zhao and Kwon [4] point out there are few studies in the literature about this important technological phenomenon although a considerable number of studies can be found regarding polymer adhesion and paper technology. Most of the latter studies focus on the perspective of paper physics.

Therefore, in this paper, the adhesion force of a lowdensity polyethylene affixed onto paperboard was studied using specific delamination equipment. The influence of 
flame treatment and two different coatings applied on the top side of the paperboard was evaluated by measuring the surface energy of the paper. The effect of starch application onto the bottom side of the paperboard was also studied. The correlation between adhesion force/surface energy of the paperboard was assessed for each experimental condition.

\section{Literature Review}

The phenomenon of adhesion between polymer and cellulose is very important in terms of composites and nanocomposites [5-8]. Alamri and Low [9] investigated the effect of water absorption on the mechanical properties of $\mathrm{n}$-SiC filled, recycled cellulose fiber-reinforced epoxy econanocomposites. The SEM results showed a clean pull out of the cellulose fibers as a result of degradation in the fiber matrix interfacial bonding, which was due to water absorption. The addition of $\mathrm{n}$-SiC was found to enhance the interfacial adhesion between the fiber and the matrix. However, the focus of the present paper is the adhesion between polymer/cellulose (paper) in laminated packaging.

Tuominen et al. [10] evaluated how corona, flame, and atmospheric plasma treatments modified the surface of extrusion-coated LDPE and PP and also the influence of these surface modifications on the print quality, that is, toner adhesion and the visual quality of the extrusion coatings. They concluded that flame treatment contributed beneficially to the print quality, on LDPE surfaces in particular, and it produced the best toner adhesion and visual quality on LDPE surfaces.

Paperboard, which is used in long-life packaging, is formed by intertwined cellulose fibers that are usually obtained from wood [11]: long fibers from pinus and short fibers from eucalyptus are commonly employed. The bottom (brown side) and the top of the paperboard are composed of unbleached and bleached fibers, respectively. A coating is also applied to the top for printing purposes. A cellulosic pulp, which is obtained by a chemical mechanical process, is used as the intermediate layer of the paperboard [11].

Good adhesion depends on an intimate contact between the surfaces. Consequently, the wetting of a liquid onto a substrate is essential, and this is characterized by the contact angle $(\theta)$ between the liquid and the solid. Low $\theta$ angles are desirable, and they signify that the liquid spreads onto the solid surface. A system is stable if $\delta_{\mathrm{S}}>\delta_{\mathrm{L}}+\delta_{\mathrm{SL}}$, where $\delta_{\mathrm{S}}$ is the solid surface tension, $\delta_{\mathrm{L}}$ is the liquid surface tension, and $\delta_{\mathrm{SL}}$ is the solid-liquid surface tension $[12,13]$.

The adhesion force to a solid increases as its surface energy increases $[12,14]$. Therefore, the surface energy of the paper is an important parameter to improve its adhesion force to the polyethylene in long-life laminated packaging $[12,14]$. Due to its nonpolar characteristic, polyethylene has a surface energy as low as $20 \mathrm{~mJ} / \mathrm{m}^{2}$. Therefore, in order to improve the adhesion force to substrates, it is common to use oxidative treatments that create polar groups on its surface $[12,15]$.

The thermodynamic work of adhesion between paper and polyethylene can be described by (1). It is defined as the energy change per unit area due to the elimination of two surfaces to create the interface between the adhering substrates [4]:

$$
W=\gamma \mathrm{P}+\gamma \mathrm{A}-\gamma \mathrm{PA},
$$

where $\gamma \mathrm{P}$ is the surface energy of the paper, $\gamma \mathrm{A}$ is the surface energy of polyethylene, and $\gamma \mathrm{PA}$ is the interface energy between paper/polyethylene.

Paper surface components, such as hydrophobic sizes, wood extractives, and fillers $\left(\mathrm{CaCO}_{3}\right.$, clay, and talc), decrease the surface energy [4]. This negative effect can be compensated by flame or plasma treatments that introduce polar groups onto the paper surface. For coated papers, the type of binder in the coating influences the adhesion of polymers. Welander and Rigdahl [16] observed that polyethylene displayed a stronger adhesion to paper coated with styrenebutadiene and calcium carbonate pigment than to a coating based on poly(vinyl acetate) binder and clay pigment.

Chen et al. [17] concluded that the addition of inorganic fillers to paper had a positive effect on the adhesion of pressure-sensitive adhesives (PSA). However, fillers can also reduce the internal strength of paper, and the benefit of adding filler is limited if the PSA is peeled from the paper in a manner that results in failure due to paper delamination.

According to Zhao and Pelton [18], peel adhesion testing is often employed to assess the bonding strength of laminated materials when at least one of the layers is flexible. They report that the use of peel measurements to characterize the interactions between pressure-sensitive adhesives (PSAs) and paper is a challenging system because failure can occur within the paper structure, as well as in the adhesive or at the adhesive/substrate interface.

The surface energy of papers ranges from 25 to $60 \mathrm{~mJ} / \mathrm{m}^{2}$, and poor adhesion onto polyethylene was observed when the critical surface tension of the paper was lower than that of this polymer $\left(\delta_{\mathrm{c}}=31 \mathrm{mN} / \mathrm{m}\right)$. Gervason et al. demonstrated that the delamination force of polyethylene-paper laminates increased with paper surface energy for different sized papers [19].

The Young-Dupre equation correlates the thermodynamic adhesion to the surface and interface energies [20]:

$$
W=\gamma l(1+\cos \theta)
$$

where $\gamma l$ is the surface energy of the liquid and $\theta$ is the equilibrium contact angle of the liquid on the solid surface.

The physical and chemical characteristics of the paper surface, such as roughness and surface energy, affect its adhesion to polyethylene. The polarity of this polymer and its surface energy also influence adhesion onto the paper. Therefore, industrial procedures for producing laminated packaging usually apply treatments such as corona, flame, and ozone to improve the adhesion between the substrates [12]. However, the scientific understanding of these treatments and the effect of different size applications are still limited.

\section{Experimental}

3.1. Materials. The following types of paperboard, which were kindly supplied by Klabin S.A., were used in this study: (a) top of the paperboard (white side) coated by a polar latex; 


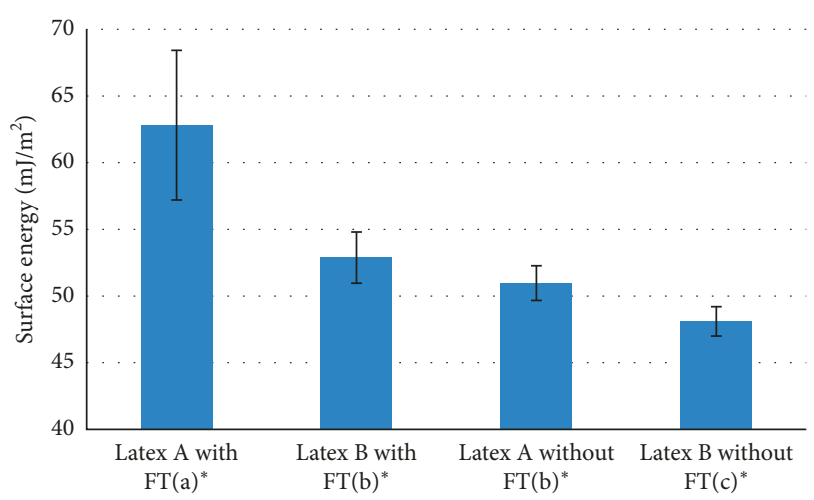

FIGURE 1: Surface energy of the top of the paperboard (white side), with and without flame treatment (FT), for both polar and nonpolar latexes (A and B), respectively. ${ }^{*}$ Letters indicates similarities between samples, according to $t$-test at $95 \%$ confidence.

(b) top of the paperboard coated by a nonpolar latex; and (c) bottom of the paperboard (brown side) both with and without starch application. For the sake of industrial confidentiality, the polar and nonpolar latexes will not be fully described in this paper and they are denominated as latex A and latex B, respectively.

A low-density polyethylene (LDPE), which was kindly donated by Braskem S.A. (with a density of $0.918 \mathrm{~g} / \mathrm{cm}^{3}$ and melt flow index of $8 \mathrm{~g} / 10 \mathrm{~min}$ ), was used in this study.

3.2. Methods. Samples of laminated paperboard/polyethylene were prepared in an extruder (Technocoat Company, Curitiba, Brazil). The extrusion was carried out at $150 \mathrm{~m} / \mathrm{min}$ with and without flame treatment on the paperboard. A polyethylene melt temperature of $320^{\circ} \mathrm{C}$ and a grammage of $12 \mathrm{~g} / \mathrm{m}^{2}$ were used to reproduce typical industrial conditions in the production of laminated long-life packaging.

3.2.1. Delamination Test: "PEEL TEST". The adhesion force between the polyethylene/paperboard was measured with the peel Test method using "Multi Test" equipment on samples that were $1.5 \mathrm{~cm}$ wide tested in $180^{\circ}$ and $100 \mathrm{~mm} / \mathrm{min}$. Ten specimens were tested for each experimental condition. An adhesive tape was applied to the polyethylene to prevent it from stretching during the delamination tests, which were carried out from a manually preseparated edge. The delamination tests for the polyethylene/paperboard top were performed using dry samples, while wet samples had to be used in the peeling test for the paperboard bottom (brown side). Otherwise, cellulose fibers were pulled out and a cohesive failure rather than adhesion was observed.

3.2.2. Roughness Measurements. A profilometer Talysurf CLI 2001-Taylor Hobson was used to evaluate the effect of flame treatment on the surface roughness of the paperboard. It was used also to measure the influence of the starch application on the roughness of the bottom surface.

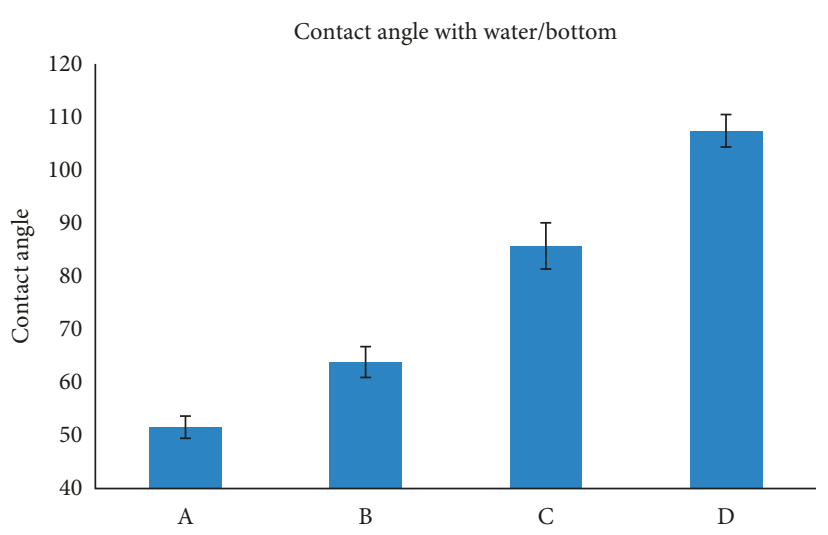

FIGURE 2: Effect of starch application and flame treatment on contact angle of water on the bottom surface of the paperboard (brown side): A: with starch/with flame treatment; B: with starch/without flame treatment; C: without starch/with flame treatment; D: without starch/without flame treatment.

3.2.3. Surface Energy Measurements (Contact Angle). The surface energy of the paperboard was calculated using contact angle measurements with diode methane and water $[13,15]$ according to the Tappi Standard (T558-om-06). The tests were kindly carried out at Henkel's laboratories in São Paulo, Brazil. Using contact angle measurements, the surface energy of the paperboard was determined by the OwensWendt method $[19,21]$.

\section{Results and Discussion}

4.1. Paperboard Surface Energy. Figure 1 shows the surface energy of the top of the paperboard (white side) with and without flame treatment for both the polar and nonpolar latexes (A and $\mathrm{B})$.

It is clear that the surface energy of the paperboard that was coated with the polar latex (A) was higher than the paperboard coated with nonpolar latex (B). Figure 1 also shows that flame treatment increased the surface energy of the paperboard coated with both kinds of latexes. It can be seen that the surface energy of paperboard coated with polar latex without flame treatment was similar to the surface energy of the paperboard coated with flame-treated nonpolar latex. Flame treatment introduces polar groups to the surface of paperboard, increasing its surface energy, promoting spreading of polyethylene and increasing adhesion [4]. As previously mentioned, a system is stable if $\delta_{\mathrm{S}}>\delta_{\mathrm{L}}+\delta_{\mathrm{SL}}$, where $\delta_{\mathrm{S}}$ is the solid surface tension, $\delta_{\mathrm{L}}$ is the liquid surface tension, and $\delta_{\mathrm{SL}}$ is the solid-liquid surface tension $[12,13]$.

It was not possible to calculate the surface energy of the bottom (brown side) of the paperboard because the diiodomethane (nonpolar liquid) was rapidly absorbed. Consequently, the contact angle on this substrate could only be measured for water (polar liquid), as shown in Figure 2. This figure shows that the starch decreased the contact angle of the water on this substrate due to its hydrophilic character. Figure 2 shows also that flame treatment improved the affinity of the substrate with water, decreasing its contact 
TABLE 1: Influence of flame treatment on roughness parameter $\mathrm{Ra}(\mu \mathrm{m})$ for the top (coated with polar latex A) and the bottom surface of the paperboard.

\begin{tabular}{lccccc}
\hline & \multicolumn{3}{c}{$\mathrm{Ra}(\mu \mathrm{m})$ top (white side) coated with } & \multicolumn{2}{c}{$\mathrm{Ra}(\mu \mathrm{m})$ bottom (brown side) } \\
\hline & $\begin{array}{c}\text { Without flame } \\
\text { treatment }\end{array}$ & $\begin{array}{c}\text { With flame } \\
\text { treatment }\end{array}$ & With starch/without flame & With starch/with flame & Without starch/with flame \\
treatment & 3.23 & 3.50 \\
Mean $(\mu \mathrm{m})$ & 0.52 & 0.50 & 3.21 & 0.13 & 0.16 \\
$\begin{array}{l}\text { Standard } \\
\text { deviation }\end{array}$ & 0.02 & 0.09 & 0.13 & & treatment \\
\hline
\end{tabular}

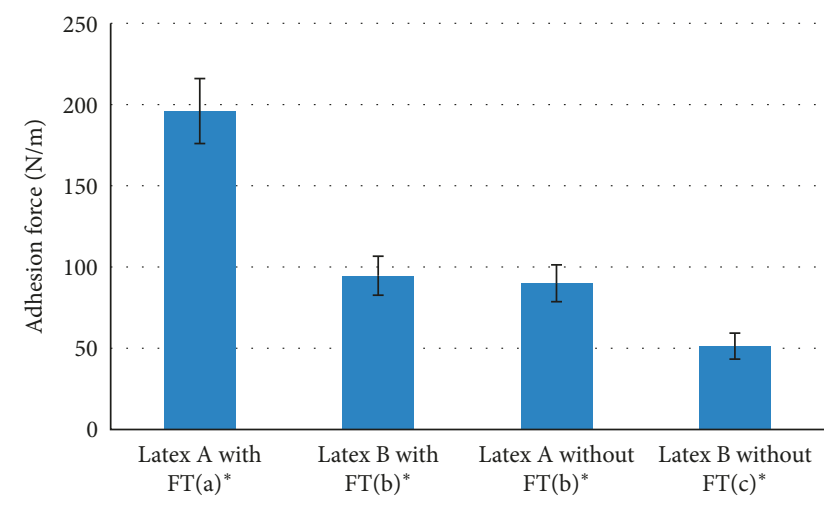

Figure 3: Influence of latex A (polar), latex B (nonpolar), and flame treatment on the adhesion force of polyethylene on the top surface of the paperboard. ${ }^{*}$ Letters indicates similarities between samples, according to $t$-test at $95 \%$ confidence.

angle on the bottom of paperboard, both with and without starch.

4.2. Roughness Measurements. The effects of the flame treatment on the roughness of both surfaces of the paperboard were evaluated because mechanical interlocking is a possible mechanism that contributes to adhesion. Table 1 shows the roughness parameter $\mathrm{Ra}(\mu \mathrm{m})$, which was measured for the top surface coated with polar latex and the bottom of the paperboard with and without starch application. It can be seen that flame treatment did not affect the roughness for both surfaces (top and bottom sides). Therefore, the influence of the flame treatment on adhesion can be mainly attributed to surface energy modification.

Zhao et al. [22] investigated the interaction between paper and pressure-sensitive adhesive by peel adhesion testing. They observed that the paper properties that influenced the peel force in the interfacial failure domain were found to be primarily the paper surface chemistry, which was characterized by the oxygen/carbon ratio (determined by XPS), and secondly, the paper surface roughness. The peel force increased with the oxygen/carbon ratio and with the surface roughness.

4.3. Delamination Test: "PEEL TEST". Figure 3 shows the influence of the A and B latexes and flame treatment on the adhesion force of the polyethylene on the top of the paperboard. It can be seen that the flame treatment significantly improved the adhesion force for both latexes. Another

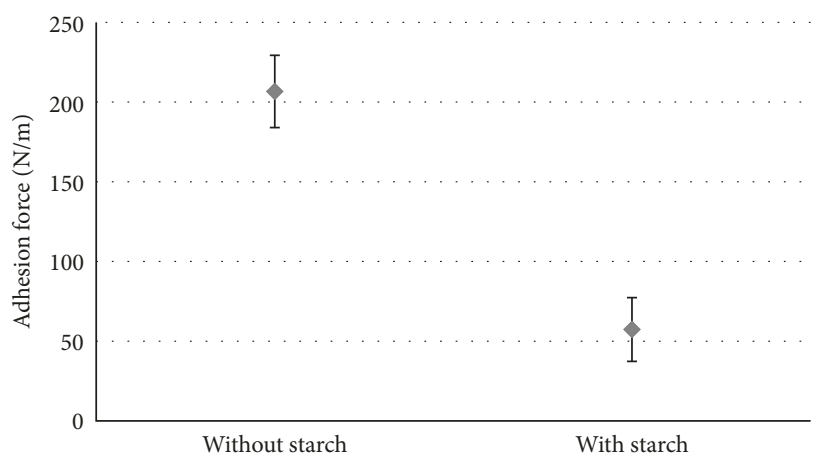

FIGURE 4: Influence of starch application on the adhesion force between the polyethylene and the flame-treated bottom surface of the paperboard.

important aspect is that the polar latex A promoted an expressive increase in the adhesion force of the polyethylene on the top of the paperboard; its effect was comparable to the application of flame treatment on the top surface, which was coated with nonpolar latex B. This result was in accordance with the surface energy values that are presented in Figure 1.

Figure 4 shows the influence of starch application on the adhesion force between the polyethylene and the flame-treated bottom surface of the paperboard. It can be seen that the starch significantly decreased the adhesion force between these components. As previously mentioned, it was not possible to measure the surface energy for the bottom of the paperboard due to the absorption of diiodomethane. However, Figure 3 shows that the starch decreased the contact angle of the water on this substrate. This effect indicated that its surface energy increased and consequently the adhesion force should have increased. Therefore, a possible reason for the lower adhesion force can be the slight decrease in the surface roughness due to the application of starch, as shown in Table 1. It should be pointed out that the use of starch is very important in order to avoid fiber release. Therefore, it is necessary to control the amount of starch applied to the bottom surface in order to balance these two opposing effects. Flame treatment is also of fundamental importance in this case because otherwise the adhesion force between the polyethylene and the bottom surface is negligible.

Figure 5 shows the adhesion force of the polyethylene as a function of the surface energy of the top of the paperboard coated with polar and nonpolar latexes, both with and without flame treatment. It can be seen that there was an excellent linear fit $(R=0.9966)$ between these two parameters. Therefore, the surface energy of the paperboard was 


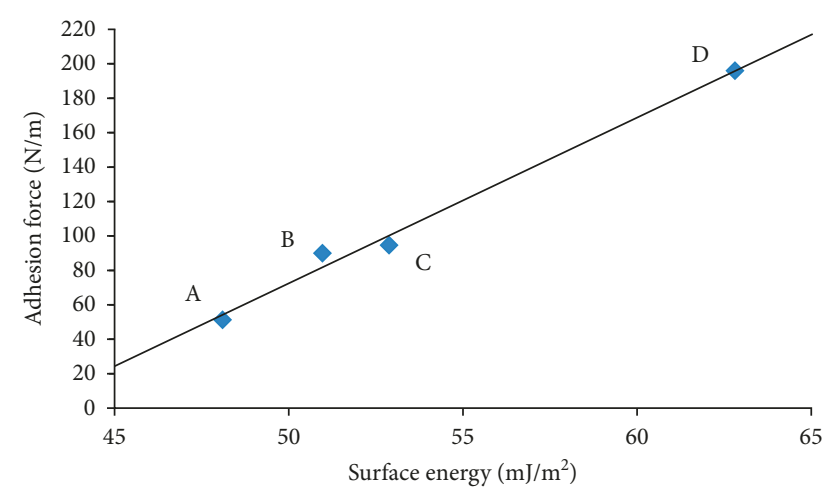

FIGURE 5: Adhesion force of the polyethylene as a function of the surface energy of the top of the paperboard coated with (A) nonpolar latex without flame treatment, (B) nonpolar latex with flame treatment, (C) polar latex without flame treatment, and (D) polar latex with flame treatment.

a direct indication of its adhesion to the polyethylene. This correlation explains why the adhesion force of the top of the paperboard coated with latex $\mathrm{A}$ and without flame treatment was similar to the adhesion force of the surface coated with flame-treated nonpolar latex B: their surface energies were almost the same. Figure 5 also demonstrates that the adhesion force of the top of the paperboard coated with polar latex (A) with flame treatment was much higher than the other three experimental conditions because its surface energy was far superior to the others.

These results were in accordance with those observed by Burnett and et al. [23]. In this study, various thermoplastic polyolefins (TPO) were submitted to different surface treatments in order to enhance their adhesion properties. The surface energies were measured using inverse gas chromatography (IGC), and the values were correlated to the mechanical adhesion testing of the painted polyolefins. Higher surface energies measured by IGC led to increased adhesion with the paint. Therefore, the aforementioned authors concluded that IGC could be used as a predictive tool for TPOpaint adhesion and mechanical substrate performance.

These results are also in accordance with those observed by Gervason et al. [19]. In their study, the surface energy of different papers treated with various sizing agents was determined by measuring contact angles. The peeling energy of polyethylene/paper was shown to follow a linear relationship versus the reversible work of adhesion. They explained this result by the fact that rupture takes place at the interface and that the size of the defect at the interface depends on the spreading coefficient.

Gervason et al. [19] mentioned that they could use the classical expression of reversible work of adhesion (1) because they were dealing with a given adhesive (polyethylene) on a series of adherents (papers). They considered also that $\gamma$ PA could be neglected in (1) since the materials used in their study were mostly nonpolar and had similar values for their surface energy. Based on these considerations, they demonstrated that fracture energy is linearly dependent on adhesion work. However, they did not show results of adhesion force versus surface energy.

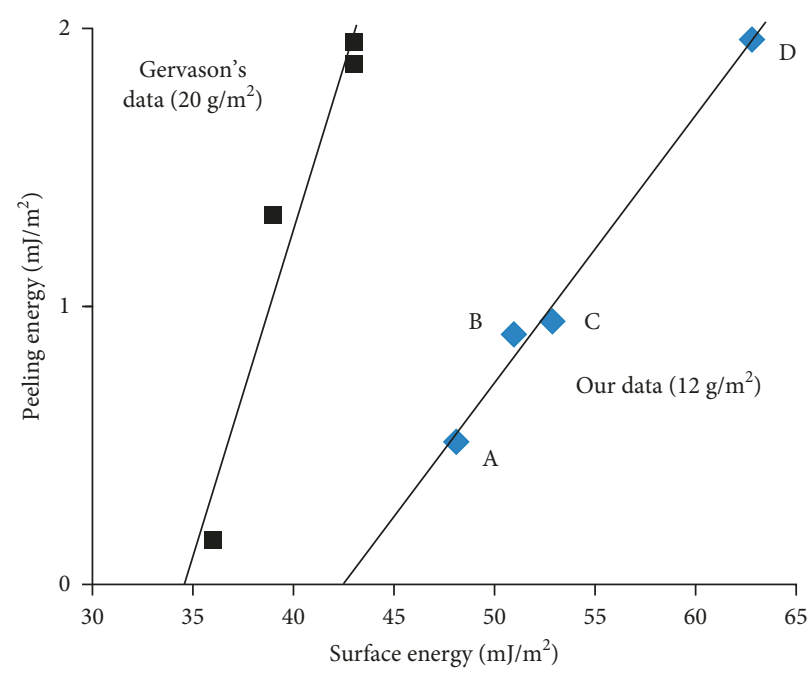

Figure 6: Peeling energy $(\delta)$ of the polyethylene as a function of the surface energy of the top of the paperboard coated with (A) nonpolar latex without flame treatment, (B) nonpolar latex with flame treatment, (C) polar latex without flame treatment, and (D) polar latex with flame treatment.

According to Aravas et al. [24], when the film deforms elastically during peeling, the peel force is a direct measure of the adhesive fracture energy. In this case, the peeling energy $(\delta)$ is given by the following equation:

$$
\delta=P(1-\cos \Phi)
$$

where $P=F / L$ is the peel force per unit width of the film and $\Phi$ is the peel angle. Therefore, as mentioned by Wei and Hutchinson [25], in steady-state peeling, $\delta$ is the work done by the peel force per unit advance of the interface crack (per unit width of film). This assumes that the contribution of overall stretch energy of the film (including residual elastic energy in the bonded film) to the work balance can be neglected [25]. As mentioned before, we have applied an adhesive tape to the polyethylene to prevent it from stretching during the delamination tests.

Figure 6 presents the peeling energy $(\delta)$ of the polyethylene as a function of the surface energy of the top of the paperboard. For comparison purposes, this figure also presents the corresponding data of Gervason et al. [19]. It may be noted that the peeling energy values obtained in the present work are very similar to those of Gervason et al. [19]. However, in our work, these peeling energies obtained for paper surface energies were higher than those reported by Gervason et al. [19]. The explanation for this difference is due to the greater thickness of polyethylene $\left(20 \mathrm{~g} / \mathrm{m}^{2}\right)$ used by Gervason to plot the peeling energy as a function of the surface energy of the paper. According to Gervason et al. [19], the increase in peeling strength with polyethylene thickness, at constant paper surface energy, can be explained by the accompanying increase of the contact area between the polymer and the adherent.

The peel test method in $180^{\circ}$, which was used in the present study to evaluate the adhesion force, provided results that were much more reliable than manual delamination, 
which heavily relies on the perception of the analyst. However, our results showed that the surface energy measurements were much more practical for quality control in the paper industry because this method can predict the adhesion force to polyethylene without preparing the laminated packages.

\section{Conclusions}

Flame treatment did not affect the surface roughness but it significantly increased the paper surface energy. The paperboard coated with a polar latex showed much higher surface energy than the paperboard coated with nonpolar latex. The application of starch on the bottom of the paperboard decreased its adhesion force to the polyethylene, which was probably due to lower surface roughness. The peel test method in $180^{\circ}$, which was used in this study to evaluate the adhesion force, provided much more reliable results than manual delamination, which relies heavily on the perception of the analyst. The adhesion force between the polyethylene and the paperboard presented a linear correlation to the surface energy of the paper for the different experimental conditions (polar and nonpolar latex, with and without flame treatment). Therefore, this study demonstrated that the surface energy of paperboard is an excellent indicator of its adhesion force to polyethylene and that it is a very reliable and practical method for quality control in the paper industry regarding the production of laminated packages.

\section{Data Availability}

The data used to support the findings of this study are available from the corresponding author upon request.

\section{Conflicts of Interest}

The authors declare that they have no conflicts of interest.

\section{Acknowledgments}

The authors would like to thank Klabin S.A., Tetra Pak, Technocoat, Henkel, Braskem S. A., Arotec, CAPES, and the Graduate Program in Materials Science and Engineering of the State University of Ponta Grossa for their support regarding the present research project.

\section{References}

[1] G. Cheney and R. T. E. Sylvester, "Factors affecting adhesion in the extrusion coating process," in Proceedings of the Polymers Laminations and Coatings Conference, pp. 1095-1100, TAPPI Press, Bangor, ME, USA, 1998.

[2] R. Dickson and P. Lepoutre, "Mechanical interlocking in coating-paper/board adhesion," in Proceedings of the Coating Conference, pp. 253-260, TAPPI Press, Atlanta, GA, USA, 1996.

[3] L. M. Oliveira, C. I. G. L. Sarantópoulos, F. G. Teixeira, and P. A. Suguiuti, "Determinação da força de adesão da metalização com alumínio em filmes plásticos utilizados em embalagens flexíveis-desenvolvimento e validação de metodologia," Polímeros, vol. 21, no. 3, pp. 233-239, 2011.

[4] B. Zhao and H. Kwon, "Adhesion of polymers in paper products from the macroscopic to molecular level-an overview," Journal of Adhesion Science and Technology, vol. 25, no. 6-7, pp. 557-579, 2011.

[5] A. L. Catto, B. V. Stefani, V. F. Ribeiro, and R. M. C. Santana, "Influence of coupling agent in compatibility of post-consumer HDPE in thermoplastic composites reinforced with eucalyptus fiber," Materials Research, vol. 17, no. 1, pp. 203-209, 2014.

[6] S. M. L. Rosa, E. F. Santos, C. A. Ferreira, and S. M. B. Nachtigall, "Studies on the properties of rice-husk-filled-PP composites: effect of maleated PP," Materials Research, vol. 12, no. 3, pp. 333-338, 2009.

[7] J. A. Simão, V. B. Carmona, J. M. Marconcini, L. H. C. Mattoso, S. T. Barsberg, and A. R. Sanadi, "Effect of fiber treatment condition and coupling agent on the mechanical and thermal properties in highly filled composites of sugarcane bagasse fiber/ PP," Materials Research, vol. 19, no. 4, pp. 746-751, 2016.

[8] J. L. Reis, J. L. Cardoso, and P. F. Castro, "Mechanical properties of recycled Kraft paper residue polyester composites," Materials Research, vol. 17, no. 4, pp. 888-892, 2014.

[9] H. Alamri and I. M. Low, "Effect of water absorption on the mechanical properties of $\mathrm{n}$-SiC filled recycled cellulose fibre reinforced epoxy eco-nanocomposites," Polymer Testing, vol. 31, no. 6, pp. 810-818, 2012.

[10] M. Tuominen, J. Lahti, J. Lavonen, T. Penttinen, J. Rasanen, and J. Kuusipalo, "The influence of flame, corona and atmospheric plasma treatments on surface properties and digital print quality of extrusion coated paper," Journal of Adhesion Science and Technology, vol. 24, no. 3, pp. 471-492, 2010.

[11] O. Vieira, Construção de modelos Empíricos e Projeto da Operação de uma máquina de produção de Cartão de Embalagem [tese], Universidade Federal do Rio de Janeiro, Rio de Janeiro, RJ, Brazil, 2003.

[12] F. Galembeck, "Superfícies de Polietileno, suas características e sua adesão," Polímeros: Ciência e Tecnologia, vol. 1, no. 1, pp. 34-38, 1991.

[13] H. Bohra, P. Fleming, and M. Joyce, "Surfaces energy of coated paper: effect of calendering conditions and relative humidity," in Proceedings of the Paper Con'09 Conference, p. 1987, Kalamazoo, MI, USA, 2009.

[14] J. Kuusipalo, "PHB/V in extrusion coating of paper and paperboard: part I: study of functional properties," Journal of Polymers and the Environment, vol. 8, no. 1, pp. 39-47, 2000.

[15] S. Greig, PB. Sherman, R. Pitman, and C. Barley, "Adhesion promoters-corona, flame \& ozone: a technology update," in Proceedings of the 2000 Polymer, Laminations \& Coatings Conference, p. 161, Chicago, IL, USA, 2000.

[16] M. Welander and M. Rigdahl, "Determination of the adhesion between low density polyethylene and coated paper," Nordic Pulp Paper Research Journal, vol. 2, no. 2, pp. 61-65, 1987.

[17] W. Chen, X. Tang, J. Considine, and K. T. Turner, "Effect of inorganic fillers in paper on the adhesion of pressure-sensitive adhesives," Journal of Adhesion Science and Technology, vol. 25, no. 6-7, pp. 581-596, 2011.

[18] B. Zhao and R. Pelton, "Peel adhesion to paper-interpreting peel curves," Journal of Adhesion Science and Technology, vol. 17, no. 6, pp. 815-830, 2003.

[19] G. Gervason, J. Ducom, and H. Cheradame, "Relationship between surface energy and adhesion strength in polyethylenepaper composites," British Polymer Journal, vol. 21, no. 1, pp. 53-59, 1989.

[20] D. Dorranian, Z. Abedini, A. Hojabri, and M. Ghoranneviss, "Structural and optical characterization of PMMA surface treated in low power nitrogen and oxygen RF plasmas," Journal of Non-Oxide Glasses, vol. 1, no. 3, pp. 217-229, 2009. 
[21] M. Żenkiewicz, "Methods for the calculation of surface free energy of solids," Journal of Achievements in Materials and Manufacturing Engineering, vol. 24, no. 1, pp. 137-145, 2007.

[22] B. Zhao, L. Anderson, A. Banks, and R. Pelton, "Paper properties affecting pressure-sensitive tape adhesion," Journal of Adhesion Science and Technology, vol. 18, no. 14, pp. 16251641, 2004.

[23] D. J. Burnett, F. Thielmann, and R. A. Ryntz, "Correlating thermodynamic and mechanical adhesion phenomena for thermoplastic polyolefins," Journal of Coatings Technology and Research, vol. 4, no. 2, pp. 211-215, 2007.

[24] N. Aravas, K.-S. Kim, and M. J. Loukis, "On the mechanics of adhesion testing of flexible films," Materials Science and Engineering: A, vol. 107, pp. 159-168, 1989.

[25] Y. Wei and J. W. Hutchinson, "Interface strength, work of adhesion and plasticity in the peel test," International Journal of Fracture, vol. 93, no. 1-4, pp. 315-333, 1998. 


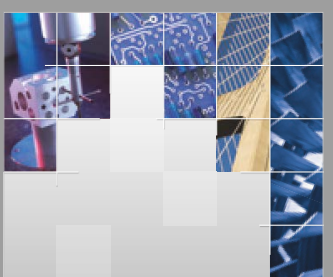

\section{Enfincering}
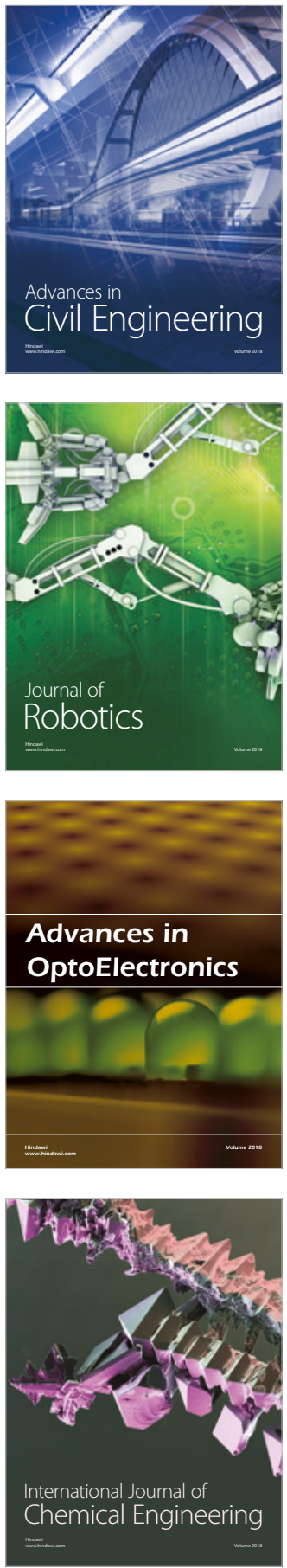

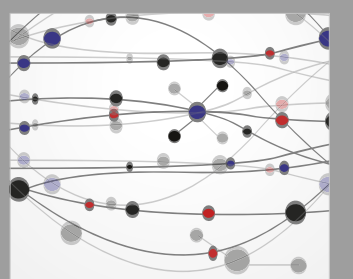

\section{Rotating \\ Machinery}

The Scientific World Journal

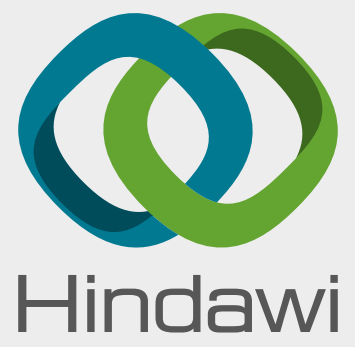

Submit your manuscripts at

www.hindawi.com
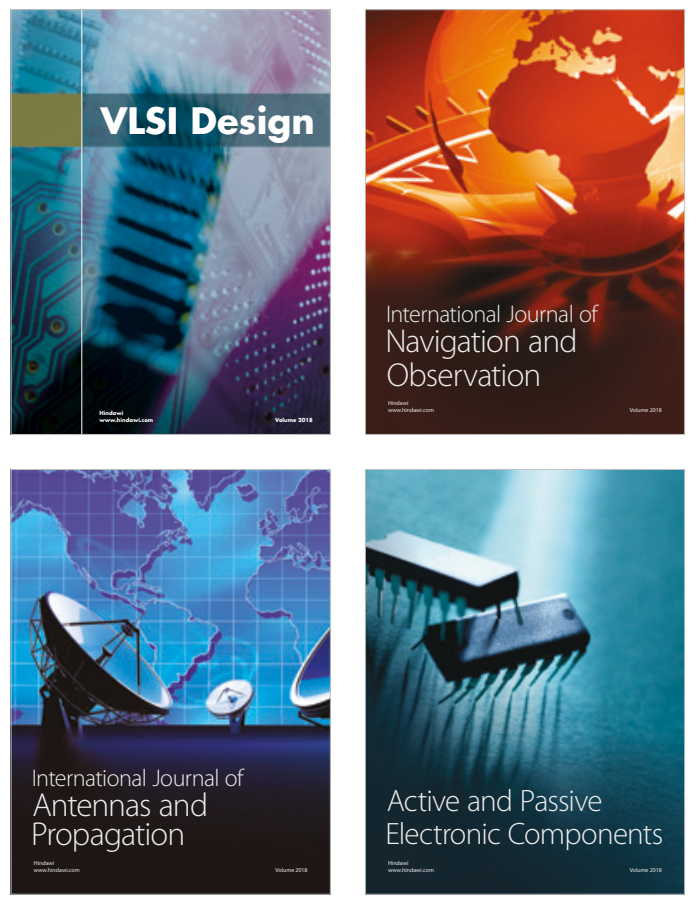
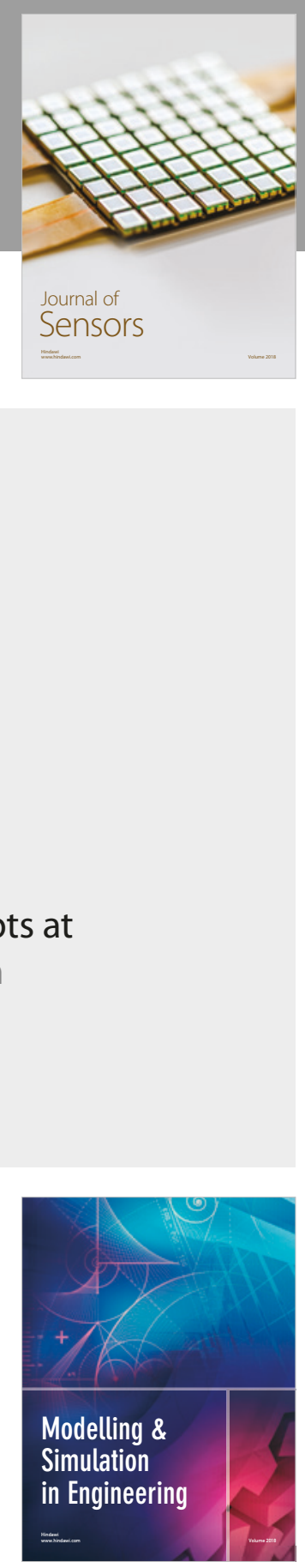

\section{Advances \\ Multimedia}
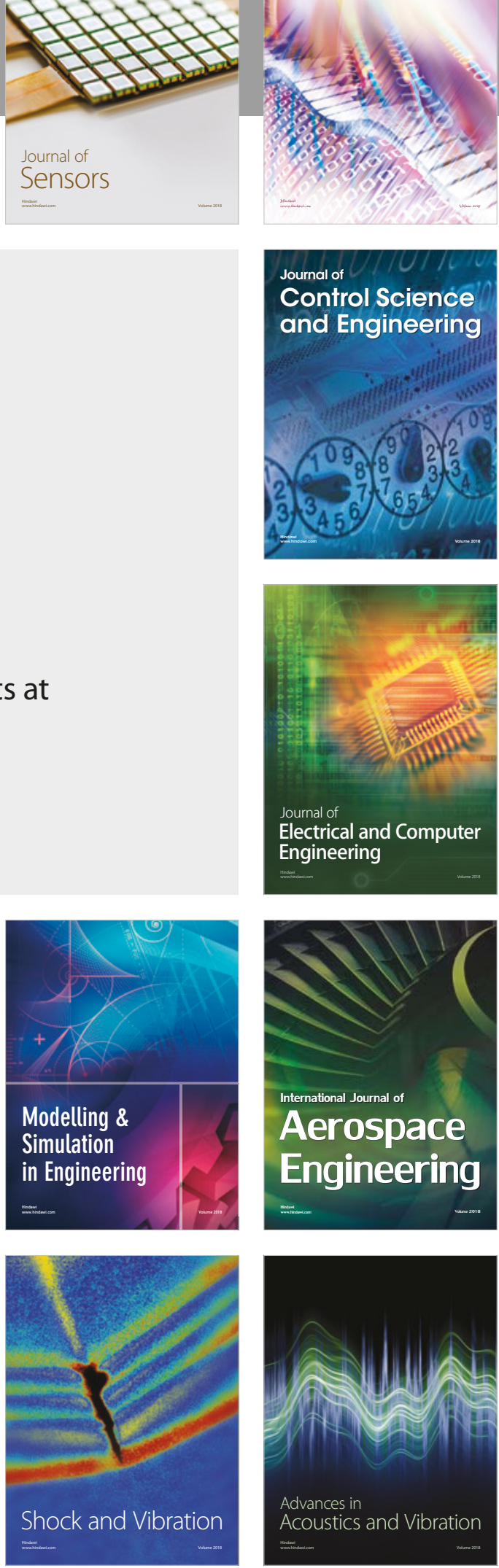